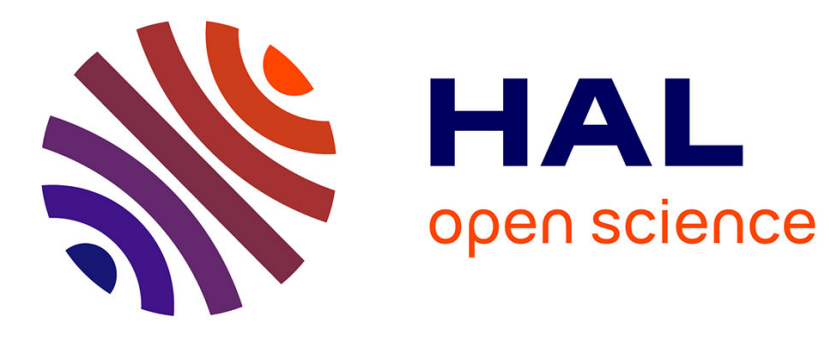

\title{
A curriculum of value creation and management in engineering
}

Bernard Yannou, Michel Bigand

\section{To cite this version:}

Bernard Yannou, Michel Bigand. A curriculum of value creation and management in engineering. European Journal of Engineering Education, 2004, 29 (3), pp.355-366. 10.1080/03043790310001658550 . hal-00748736

\section{HAL Id: hal-00748736 https://hal.science/hal-00748736}

Submitted on 16 Mar 2013

HAL is a multi-disciplinary open access archive for the deposit and dissemination of scientific research documents, whether they are published or not. The documents may come from teaching and research institutions in France or abroad, or from public or private research centers.
L'archive ouverte pluridisciplinaire HAL, est destinée au dépôt et à la diffusion de documents scientifiques de niveau recherche, publiés ou non, émanant des établissements d'enseignement et de recherche français ou étrangers, des laboratoires publics ou privés. 
Yannou B., Bigand M., (2004), A curriculum of value creation and management in engineering. European Journal of Engineering Education, vol. 29(3, DOI: 10.1080/03043790310001658550): p. 355-366.

\title{
A curriculum of value creation and management in engineering
}

\begin{abstract}
BERNARD YANNOU ${ }^{1}$, MICHEL BIGAND ${ }^{2}$
As teachers and researchers belonging to two sister French engineering schools, we are convinced that the processes of value creation and management are essential in today's teaching of industrial engineering and project managers. We believe that such processes may be embedded in a three-parts curriculum composed of Value Management and Innovation Management courses linked to the practice of group projects so as to actually acquire value and innovation spirit, reflexes, and professional skills. After a cogitation about the need for such knowledge and skills and a listing of an ideal value and innovation curriculum, we are presenting our solution for a short and efficient training on value creation and management in engineering.

Enseignants au sein de deux écoles d'ingénieurs françaises, nous sommes convaincus que l'enseignement des processus de création et de management de la valeur est essentiel dans le formation de chefs de projets et de responsables industriels en ingénierie. Nous pensons que de tels processus sont bien traduits par un programme d'études en trois parties composé de cours sur le management par la valeur et le management de l'innovation, cours liés à une pratique de projets en groupe de manière à réellement acquérir l'esprit valeur et innovation, les bons réflexes et savoir-faire. Après une première réflexion formelle sur le besoin en connaissances et aptitudes à acquérir concernant un programme d'études idéal sur la valeur et l'innovation, nous présentons notre solution pour une courte formation en création et management de valeur en ingénierie.
\end{abstract}

\section{Introduction: A need for value creators and managers in companies}

Both authors teach industrial engineering within two sister French engineering schools that recruit students after a two-years' preparation course ${ }^{3}$. Both institutes ${ }^{4}$ are generalist engineering schools with imposed courses of various engineering disciplines and few elective courses during the two first years of education. A specialization only occurs during the last third year ${ }^{5}$. The choice is deliberately made of a large scientific and technical learning, with thorough insights into scientific and technical courses of various disciplines. But it would be a nonsense to keep this strategy unchanged along the three years of education. Indeed, students must know how to put this knowledge in action when confronted to a concrete scientific issue or industrial project. This is particularly a challenge in such engineering schools where:

\footnotetext{
${ }^{1}$ Laboratoire Génie Industriel, Ecole Centrale Paris, 92295 Châtenay-Malabry, France. email: yannou@1gi.ecp.fr

${ }^{2}$ Équipe de Recherche en Génie Industriel, Ecole Centrale de Lille, Cité Scientifique, BP 48, 59651, Villeneuve d'Ascq, Cedex, France. e-mail: Michel.Bigand@ec-lille.fr

${ }^{3}$ Classes préparatoires aux grandes écoles d'ingénieurs.

${ }^{4}$ Ecole Centrale Paris and Ecole Centrale Lille.

${ }^{5}$ Specialization in mechanics, electronics, finance, industrial engineering, civil engineering, biology, applied mathematics, physics, chemistry, material sciences, project management and creation of start-up companies.
} 
Yannou B., Bigand M., (2004), A curriculum of value creation and management in engineering. European Journal of Engineering Education, vol. 29(3, DOl: 10.1080/03043790310001658550): p. 355-366.

- scientific theories are considered as of utmost nobility,

- there is little time to transmit this trans-disciplinary philosophy of action; the message must therefore be clear, efficient and convincing,

- $\quad$ students are not prompted to work in groups after their tough two or three years' preparation course since they have worked individually so far and often have considered they were involved in a competition.

It would be vain to even envisage teaching only a scientific core without learning a trans-disciplinary policy of action. We believe that this lacking part actually corresponds to a learning and practice of the processes of value creation and value management.

The two authors have defined together a core of complementary courses to progressively sensitize students in that sense along the first two years and to efficiently train them for the third year specializations such as industrial engineering, project management and start-up creation. For these courses, the targeted appointments within companies are project managers and industrial managers.

In a context of a global market place, companies of industrialized countries are more and more compelled to transfer their production to developing countries. Their situation of relatively low salaries and their increasing competitiveness in technical skills inevitably compete with the gains in productivity of our countries which remain bounded. Some countries as India and China already train high level technicians and industrial managers. Our companies are doomed to keep ahead in research and development and in high technologies by constantly innovating and creating new values. Innovation is an imperative. Companies must be proactive while adopting more systematically approaches of technological and scientific surveys, developing creativity within industrial processes, managing innovation at all stages, managing value for the different stakeholders all along the products and services lifecycle and managing their knowledge (Karlsson and Ahlstrom 1997).

Targeting this goal, one defines in section 2 the need in an ideal curriculum (i.e., functional specifications) on value creation and management in engineering. Section 2.1 exposes some important notions and concepts introduced in the European standard on Value Management (EN-12973 2000) and for which methodologies and tools must be provided and then taught. In section 2.2, we extend the conventional understanding of functional approaches and value approaches in a multi-disciplinary way and we propose to join the important additional concepts of innovation processes and convergence processes that we believe to be necessary to an ideal curriculum. Once the problem set up, the next three sections present our solution of a quite brief training in value creation and management in engineering: a course on Value Management (in a broad sense) in section 3, a course on innovation management and techniques in section 4 and an acquisition of good practice within a framework of project experimentations in section 5. A discussion on the efficiency of this curriculum is performed in section 6 .

\section{Our understanding of value creation and management}

\subsection{Our understanding of the standard Value Management}

Value Management is a recent methodology, standardized in 2000 (EN-12973 2000). It can be defined as a new style of management as well as a problem solving technique for high level issues in companies. It is a natural evolution of Value Analysis and Value Engineering developed in the forties and fifties (Miles 1961). Hereafter, let us present a summary of Value Management while highlighting key notions in bold.

In a company, every important strategy of management to build or every management decision to make is prepared and performed as any project of: 
Yannou B., Bigand M., (2004), A curriculum of value creation and management in engineering. European Journal of Engineering Education, vol. 29(3, DOl: 10.1080/03043790310001658550): p. 355-366.

- $\quad$ innovative design or redesign of a product that the company wants to include in its product portfolio,

- innovative design or redesign of a service linked to a product and provided to the customer, or of an internal service of the company (accounting system, reengineering of a production line or a delivery service...).

Value Management consists in listing the different needs of the stakeholders, examining existing potential solutions and gathering potentially interesting information through appropriate surveys, expressing needs into more detailed functional requirements (that will constitute a reference framework for future assessments), identifying sources of added values to target the efforts in view of innovating, innovating at different promising locations, proposing a short-list of aggregated consistent solutions/scenarios, assessing these solutions in terms of costs and values, making a final choice, making recommendations and supervising the detailed design or precise implementation, capitalizing the knowledge of the VM operation.

This overall VM process is well detailed in (EN-12973 2000) as a sequence composed of 10 stages. A VM operation is performed by a working group composed of representatives of the company departments the most involved and of other important stakeholders (product users, purchaser, dealers, transporter...). A participative approach is always prompted when necessary.

A general definition of value is provided as the relation between the satisfaction stakeholders will have for a given solution/scenario with regards to their initial needs and the amount of resources that have been required. Despite this rather loose definition, people are prompted to develop their own metrics of values.

A VM operation must be in accordance with the company's program it is embedded in and more generally it must contribute to the overall company's strategy. The company must constantly develop a value culture so as to ensure the best results for VM operations. The consideration of stakeholders in a broad sense naturally includes the environmental concerns or impacts related to the implementation of the chosen solution/scenario. A VM approach guaranties a sound quality approach.

In addition, the VM standard (EN-12973 2000) mentions methodological tools currently used at different stages and the link with other comparable approaches as design-to-cost or design-to-objective.

\subsection{Extending somewhat the scope of value creation and management}

Even if Value Management appears to be a pertinent and maybe unique global framework to deal with creation and management of values, we did not want to stop at that. As in an innovation process, we wanted to consider the founding concepts of VM so as to define a broader curriculum around VM. We believe that VM is founded on four main concepts: functional approaches, value approaches, innovation processes and convergence processes.

Functional approaches provide a way to express needs and objectives, to check the completeness, soundness, tractability of objectives or requirements, to rank or rate them, and to trace the deployment of theses objectives into solutions. Our course aims to present the wide scope of functional approaches. Basically, Functional Analysis (BernardBouissières 2000) is a set of considerations, tools and procedural actions leading to a functional representation useful for Value Analysis practitioners (Apte 2000), to benchmarking analysis of concurent products/services and to reliability analysis. The Function/Structure/Behaviour model (Umeda, et al. 1996) is considered as a major product design theory. The recursive deployment of a function-structure model relating the different levels of specifications and of product and process solutions in a company is also worth 
Yannou B., Bigand M., (2004), A curriculum of value creation and management in engineering. European Journal of Engineering Education, vol. 29(3, DOl: 10.1080/03043790310001658550): p. 355-366.

mentioning. It is implemented by System engineering software supports and standards for managing industrial processes as ANSI EIA 632 (1998).

Value approaches allow to express indicators as balances between the fulfilment of the objectives and the consumption of resources (possibly the costs), these indicators serving for benchmarking, value diagnosis for innovation or reengineering targeting, solution assessment, and more generally to conduct the problem solving process. We also present the "value-oriented view" of a firm, well reflected by Porter's concept of Value Chain (Porter 1986) that considers a firm as a process of value creation consuming and transforming input values in order to provide clients and other stakeholders with output values. We also emphasize the issue of value measurement, often neglected, but that appears to us as one of the most complex since it involves many disciplines: psychophysics (sensorial analysis, measurement theory (Stevens 1951)), mathematics (statistics, data mining...), marketing with a technique as conjoint analysis (Green and Srinivasan 1978) and Multi-Criteria Decision Analysis (MCDA) with ranking and rating techniques as: Pairwise Comparison (Limayem 2001), Analytic Hierarchy Process (Saaty 1980) and utility-value theory (Fernandez, et al. 2001).

Innovation processes create new values since, according to Higgins (Higgins 1994), "creativity is the process of generating something new that has value". Innovation processes may be split into innovation techniques and innovation management.

Innovation techniques may be:

- creativity tools; they can be classified into two categories (Lambin 1991): intuitive tools coming from works on group psychology (such as brainstorming, nominal groups, analogical methods), and rational tools coming from more systematic procedures (such as discovery matrices, morphological analysis, Functional Analysis).

- $\quad$ the TRIZ methodology (Savransky 2000) for product reengineering, which is based on a set of tools (contradiction matrices, ARIZ systematic invention algorithm, evolutions laws...) established from the permanence of innovation mechanisms in patents and on the permanence of innovation trajectories of families of physical systems.

Innovation management can address various issues as: coordination and processes for the use of innovative tools (Ngassa, et al. 2003), technological and economic surveys, patent policy, employee involvement policy, working group composition policy, competency management, economic intelligence, company strategy (brand image as Renault), partnership policy...

The convergence processes in group problem solving must also be adequate and optimal in the working and organisation modes, the information exchange and the project management itself. Here, Value Management (EN-12973 2000) brings a valuable working framework as described in the previous section. This is why VM is the backbone of our curriculum. However, we also mention that some other frameworks, that we believe less complete, also try to provide such frameworks for guiding actions in an industrial context. Let us mention the Balanced Scorecard (Kaplan and Norton 1996), the Activity-BasedCosting method and possibly Multi-Criteria Decision Analysis frameworks (Roy 1985). Moreover, VM practitioners usually adapt their methodologies on the type of problems, on the economic challenge (the deployment of a VM operation is also devised so as to optimise the value for the company) and on the practitioner's culture itself. Thus, a theoretical course on VM has to present a panel of practical case studies. Finally, as "value creation and management" are related with many aspects, our curriculum also refers to: concurrent engineering, knowledge management, problem solving, group psychology, project management, system engineering, requirement engineering, risks, total quality 
Yannou B., Bigand M., (2004), A curriculum of value creation and management in engineering. European Journal of Engineering Education, vol. 29(3, DOI: 10.1080/03043790310001658550): p. 355-366

management, six-sigma, marketing, sociology, organization theories, eco-design and sustainable development.

\section{A Short Function and Value based course}

We defined several years ago a short "Function and Value based course". It is based on the requirements exposed in sections 2.1 and 2.2. A Value Management framework is adopted and some incursions are made into other disciplines also dealing with value concerns as: marketing, sociology, finance and management (value chains), decision making, system engineering... The course is repeated by groups of 30 students and split into 10 sessions of 3 hours. The sessions are described hereafter.

\section{Session 1: Discovery of Functional Analysis on products}

The first session is a workshop. Its aim is to discover important notions of Functional Analysis in an inductive way through the manipulation of well known products. Six products of the same kind are presented and shared between 6 groups of 5 students. Each group is asked to successively answer a certain number of questions, each set of answers leading to animated debates between the groups. In that way, students discover by induction the important notions of Functional Analysis (main need, service functions, technical functions, functional performances, design principles).

\section{Session 2: Generalization to processes}

The same workshop principle is followed to study an administrative process and next a managerial process so as to deduce that the important notions discovered are similar.

\section{Session 3: Then 10 structured stages of a VM operation - The project}

In this session, the contexts of Value Analysis and Value Management are presented: definitions, spirit of value (VM definition (EN-12973 2000), polysemy of value (Ben Ahmed and Yannou 2003)), economical views of value (Perrin 2001), historical motivations, standards, the working group, the ten stages (role, conditions of implementation, deliverables). Other notions related to an industrial project are presented: recursive deployment of a function-structure model, different levels of specifications, $\mathrm{V}$ cycle, ANSI EIA 632 (ANSI/EIA-632 1998) standard on industrial processes is evoked. Some examples of Value Management operations are provided.

\section{Session 4: External Functional Analysis - set of Functional Requirements}

A methodology for establishing a set of Functional Requirements is taught:

- Main need, frontiers of the object studied, systems embedded

- $\quad$ Product Lifecycle, list of life phases. For each phase, list of agents and other systems interacting with the object, list of service functions

- Logic for the determination of the expected/desired functional performances (also called appreciation criteria) and of their quantification (scale and context of measurement, expected levels, value bounds, flexibility on the specification)

- Functional hierarchies.

\section{Session 5: Sociological contributions to VA and VM operations}

Some sociological aspects of product and service values are presented: the changes in product values, fashions, image of a product through our personal values and culture, cultural influences on the value perceived, sociological survey. 
Yannou B., Bigand M., (2004), A curriculum of value creation and management in engineering. European Journal of Engineering Education, vol. 29(3, DOl: 10.1080/03043790310001658550): p. 355-366.

\section{Session 6: Marketing contributions to VA and VM operations}

Some interesting marketing approaches have been adapted to a VA/VM approach as Goyhenetche's (1999), and others are also adapted to innovative products (Bloch and Manceau 2000). These approaches are worth knowing since they adequately complement the qualification and the quantification of the needs and of the service functions.

\section{Homework: Set of Functional Requirements}

Students by groups of 5 work, out of session, on the primary stages of a VM operation, up to the establishment of the set of Functional Requirements.

\section{Session 7: Internal Functional Analysis - Value diagnostic}

Acquisition of: relations between service functions and technical functions, assessing the costs (of elementary parts for a product and of resources and elementary activities for a process) and dealing out the costs between service functions. Benchmarking of a set of solutions with regards to the costs of service functions. Value diagnosis on an existing solution: Which service function must be redesigned in priority due to its low value or its non contribution to the overall result? Where and why is it interesting to innovate? After the improvement of several potential solutions, how to make a choice between these solutions on a value basis (see session 9 for a global solution rating).

\section{Session 8: Industrial testimony of a consultant on value chain audit and redesign (Porter 1986)}

\section{Session 9: Multi-Criteria Decision Analysis for a VA/VM operation}

Different aspects of the problem of quantification and decision making are tackled as this is a crucial issue in the following VA/VM stages:

- qualification of a set of measurable, complementary, non redundant appreciation/assessment criteria for a service function (see session 4) and their quantification,

- $\quad$ ranking and weighting/rating the service functions (see session 4) starting from the functional tree: notions Multi-Criteria Decision Analysis (MCDA) techniques to compute a global rate from the functional tree, notions on the Conjoint Analysis technique of marketing (Green and Srinivasan 1978) and on the utility-value theory.

- $\quad$ these same methods are used to make a choice between different potential solutions (see session 7). One of the authors (Yannou 1999) proposed a quantitative approach adapted from MCDA techniques to make a choice on a value basis.

\section{Session 10: Links with other methods and conclusion}

The links with the following methods are evoked: Design-To-Cost, Design-ToObjective, Quality Function Deployment. A conclusion on a VA or a VM operation is drawn.

This course intervenes just before a concrete project in the Project-Activity context (see section 5.2) consisting in the design and realization of a product, service or organization prototype.

\section{A Short Innovation Management and Techniques course}

A second course on «Innovation Management and Techniques » complements the « Function and Value based course ». Innovation is tackled in three ways:

1. Culture (30 hours): Multiple views of innovation in companies. 
Yannou B., Bigand M., (2004), A curriculum of value creation and management in engineering. European Journal of Engineering Education, vol. 29(3, DOl: 10.1080/03043790310001658550): p. 355-366.

2. Techniques (15 hours): Some tools/techniques for creativity.

3. A structured approach (15 hours) compatible with a VM framework.

\subsection{Innovation culture}

Innovation may be present in many forms and many disciplines within a company. Different evocations of an industrial culture of innovation are discussed along 103 -hour sessions that are mainly industrial testimonies:

1. A deliberate choice of an innovative product strategy - Advantages and drawbacks.

2. Innovating in the market - Typical products, markets and marketing techniques. Must we always innovate?

3. Innovation and protection. The technical and economical strategies for patenting and trademarking. The strategic lever of a patent, the patent licensing policy. Internal employee motivation policy for patenting.

4. The recent use of TRIZ methodology in automobile. Difficulties of innovation apprenticeship.

5. Prompting innovation in multi-partnership projects. Testimony of a new win-win partnership policy in automobile projects.

6. Innovation throughout the history of products and technologies

7. How to innovate in multi-cultural groups? Knowing the cultural differences (Latins, Asians, Anglosaxons) to innovate better.

8. Economic intelligence and innovation

9. Innovating in short projects - A necessary cooperation between $\mathrm{R} \& \mathrm{D}$ and project organization.

10. Knowledge Management favors innovation. A recognized fact but difficult to assess.

\subsection{Innovation techniques}

Innovation techniques are not taught as a collection of micro-tools and techniques but they are approached in a more general manner.

We present the students with the classification of Wallas (Wallas 1926) that considers four stages in the creative process which can be found in all innovation techniques: preparation, incubation, illumination, verification. We simplify the presentation of innovation techniques in classifying them into 10 families (Ngassa, et al. 2003): brainstorming, checking list, excursion, matrix of criteria, notebook, mind map, role, relaxation, perseverance, others. Finally, we teach them a special integrated method for product, service and organization innovation (Ngassa, et al. 2003).

We also pay a special attention to knowledge management (especially acquisition) during the innovation stage. Knowledge has to be integrated with the aim of improving creativity in the design process at two levels. Firstly, by helping designers to extract information from the social, technical and economical environment and to organize it in an appropriate manner. Secondly, by assisting them for an optimal use of this knowledge, especially in the search for innovative solutions. At this stage, we prompt the students to consider four classes of useful knowledge: product/service/organization knowledge, practical knowledge (information about the company's know-how), principles of physics, patent documents. Some supporting tools for each of these knowledge types are presented and a framework for acquiring and managing this knowledge is proposed; later, during their Project-Activity (see section 5.2), students are encouraged to use them. 
Yannou B., Bigand M., (2004), A curriculum of value creation and management in engineering. European Journal of Engineering Education, vol. 29(3, DOl: 10.1080/03043790310001658550): p. 355-366

\subsection{A structured approach of innovation processes}

An innovation and design process, somewhat extending a typical VM process, is presented to students. It consists of a succession of three stages: knowledge acquisition (previously evoked), creativity, product/service/organization design. The second stage of creativity is itself composed of 6 stages: 1) a problem identification (to better identify the actual problem to solve), 2) an inventory of the ideas previously imagined (and the cause of their abortion), 3) a precise definition of the criteria and constraints for acceptation of a new solution, 4) an use of creativity tools to find new ideas, 5) an assessment of the potential solutions with regards to the criteria and constraints and 6) the combination of different solutions to better respect the criteria and constraints. This overall scheme has already been applied and validated on a large number of industrial and pedagogical projects.

This course in "innovation management and techniques" is directly experimented in the Project-Activity in which students are prompted to innovate on products, services, organizations, or a combination of these elements. A highly successful project in terms of innovation may look like the following: a team of students has designed and realized a prototype of headphones allowing the reconstitution of 3D sound. This design has been patented and several students have created their own company to develop and market their new product. The patent document and the business plan for the creation of a company were typical deliverables of the Project-Activity. We believe they are of utmost value for companies.

\section{Acquisition of good practices by project experimentations}

\subsection{Acquisition of competences for creating value}

Keeping in mind that one would like to train value creators and managers, we had to define what we heard by manager. Somewhat inspired by the consideration of the ten managerial roles depicted by Mintzberg (Mintzberg 1973), a teaching team (Bigand, et al. 2000) elaborated a "map of competence" so as to detail the competences a project/industrial manager should show, and to supervise and check that the training system fosters the use and the development of these competencies. Eight main competencies, further detailed into items (see table 1) are considered for our students: to design, produce, innovate, drive, organize, communicate, teach, undertake. This map of competence is used as a spreadsheet to describe each pedagogical act as a contributor to the improvement of the competences. When comparing the contributions of courses and other pedagogical activities, the ProjectActivity (see section 5.2) appears as essential since it is the only activity which covers a number of expected competences. In consequence, the students are aware that their assessment of these competences must imperatively be successful.

\begin{tabular}{|l|l|}
\hline \multicolumn{1}{|c|}{ Competency } & \multicolumn{1}{c|}{ Item } \\
\hline To design & $\begin{array}{l}\text { To formulate a problem, To formalize, To model, To imagine solutions } \\
\text { from the model, To chose satisfactory solutions }\end{array}$ \\
\hline To produce & $\begin{array}{l}\text { To transform a realistic model and ensure its feasibility, To experiment, To } \\
\text { produce }\end{array}$ \\
\hline To innovate & $\begin{array}{l}\text { To mobilize and stimulate personal or team creativity, To be open-minded } \\
\text { to outer ideas and environment, To target creativity toward an objective }\end{array}$ \\
\hline To drive & $\begin{array}{l}\text { To structure and valorise a project, To egg on dynamics in a project, To } \\
\text { ensure the project management }\end{array}$ \\
\hline To organize & $\begin{array}{l}\text { To make use of appropriate means and methods to ensure information } \\
\text { exchange or instructions between the actors of a system }\end{array}$ \\
\hline
\end{tabular}


Yannou B., Bigand M., (2004), A curriculum of value creation and management in engineering. European Journal of Engineering Education, vol. 29(3, DOl: 10.1080/03043790310001658550): p. 355-366.

\begin{tabular}{|l|l|}
\hline To & To regulate and control the evolution of an organizational system \\
communicate & $\begin{array}{l}\text { To exchange clear and precise information, To be open-minded to outer } \\
\text { ideas and environment, To develop an ease-to-contact feeling, To organize } \\
\text { information flow using adapted methods and tools, To argue orientations }\end{array}$ \\
\hline To train & $\begin{array}{l}\text { To select people who will receive a training, To elaborate a training plan } \\
\text { To supervise all or a part of a training, To assess the people's progress }\end{array}$ \\
\hline To undertake & $\begin{array}{l}\text { To manage, To market, To create value, To negotiate, To evaluate risks, } \\
\text { To be autonomous }\end{array}$ \\
\hline
\end{tabular}

Table 1: Expected competences for a project and industrial manager.

\subsection{Committing students in value creation and management through the Project-Activity}

Project-Activity started 10 years ago (Bigand, et al. 2000). A team of students must lead a project to design, prototype and industrialize a product, a service, an organization or a combination of these elements. The project lasts two years (about 300 hours per student); the project is performed in cooperation with external partners (industrial partners interested by the innovation and/or by sponsoring, professional trusts and institutions, suppliers), and under the guidance of a team of teachers. The subject must basically have a scientific and technological dimension, but the students will have to take all the following dimensions into account: economical, environmental, cultural, commercial... It is imposed that several scientific fields be concerned by the project (e.g. a subject dealing with the sole computer science would not be accepted). Indeed, value is also nested into multidisciplinary approaches.

The students define their own subject, they start by appealing to their own creativity, producing some value by themselves and we let them the opportunity to develop a personal craze. They have to set up the engineering problem and to specify the context and the expectations of the project. Then, they become genuine actors of their own training. The subject is validated, at a sufficiently early stage of the process, by the teaching team playing the role of a steering committee whose approval the students have to seek. A scientific supervisor is chosen within the teaching staff. His/her role is to validate the main orientations of the project (objectives, scientific approach, specific training plan for the team, ...) and to help gathering the advisory team. Relationships with external partners (other advisors, industry, etc.) are generally undertaken by the team of students, the advisors intervening when asked.

A written document describing the need is elaborated by the team and presented to the teachers and partners three months after the beginning of the project. After validation, solutions are explored by the team, using innovation and design techniques and methods. The choice of the solution is made and collectively validated. The team of students must then elaborate the estimated project planning. Another written document is presented by the students (about 6-8 months after the beginning) and the realization stage may start.

During the phase of realization, the team must manage the project; for the teachers, the aim is to prevent rather than to heal: a real-time monitoring is preferred to a system of a posteriori assessment. Periodically, a meeting is organized by the student with the main actors of the project to control the progress of the project. A pilot is appointed for each project: It is a lecturer in project management whose mission is to help the team and to make the other actors aware of the difficulties to come.

At the end of the project, an oral presentation is organized, and a written report is delivered by the students, as well as a prototype. 
Yannou B., Bigand M., (2004), A curriculum of value creation and management in engineering. European Journal of Engineering Education, vol. 29(3, DOI: 10.1080/03043790310001658550): p. 355-366.

\section{Discussion and conclusion}

We are not the first ones to propose a curriculum concerning the training of future engineers to value management and creation. Seni (2001) and Woodhead (2002) for example already proposed such a curriculum. Nevertheless, they are much more centred on Value Management and on other management techniques than we believe we are. We are probably more centred on engineering with the challenge to, at he same time:

- train students to effective techniques: creativity tools, value analysis of products, value management, practical decision making considerations...,

- give students a large culture on value and innovation in a company,

- make them experiment and refine sound human managerial reflexes and competences.

We presented the progress of two courses on "Function and Value" and "Innovation Management and Techniques". These two courses are directly implemented in a two-years' Project-Activity within a team of 4 to 6 students.

There are a number of indicators that prove the effectiveness of such a curriculum. For almost 10 years now, we have noticed the high motivation of students who perfectly understood this value creation and management curriculum, but also the motivation of all the teachers involved in this process. Much more than motivation, such an approach changes the mentalities and triggers a proactive behaviour for students as well as for teachers. By example, the teachers meet in the projects' steering committees, consequently they now better know each other, resulting in a number of benefits and value for the institution, e.g. in a better unity of mono-disciplinary courses.

Project-Activity is an ideal method for acquiring a scientific multidisciplinary knowhow and managerial competences, in addition to the traditional mono-disciplinary courses. The students improve their value in a tremendous manner for both aspects and after two years are able to produce actual value in industrial projects. Indeed, at the beginning of the Project-Activity, this is often the first time students face a badly and fuzzily expressed problem and have to detail objectives and to organize themselves to meet these objectives within a given duration while using limited resources (or finding them) and acquiring some identified knowledge. To meet the objectives, they design, experiment with many possible solutions, and produce. It is clear, from the definition given in section 2.1 , that they basically deal with value creation. This value creation is directly assessed for each student and for the group (with the map of competences, see section 5.1) as well as for the result of the project (with the objectives defined for the product and the project) at the end of the project through appropriate forms filled by the scientific supervisor and the students. For an industrial partner, the produced value can take several forms, as innovation (in this case, the firm can generally recover the intellectual property and patent the innovation), market and information survey (sometimes realized with the aid of students of a business school), concrete realization (often a prototype) and associated documentations (among them: a CDrom, a web page, a poster and most of the time: a user's documentation, a technical documentation and an experience debriefing of the project).

Our experience of this supervised Project-Activity shows that it is a fantastic way to teach many aspects of value creation for a project and industrial manager. Teachers and students appeared to be highly motivated and enthusiastic. It is also a way for the institution to exchange with companies and to promote an innovative image. After 10 years, companies provide by themselves more and more project subjects, often consisting in developing or refining an innovation on a product or on a service. They also more and more participate voluntarily to the juries and to the day-to-day technical support and supervision. This commitment of companies undoubtedly fostered the hiring of our students since companies say that they highly appreciate such a curriculum. 
Yannou B., Bigand M., (2004), A curriculum of value creation and management in engineering. European Journal of Engineering Education, vol. 29(3, DOI: 10.1080/03043790310001658550): p. 355-366.

Several of our colleagues (cf. (Verzat, et al. 2002)) undertook to study the long-term influence of a given educational system in engineering colleges on the future entrepreneurship of engineers during their careers. This study has been grant-aided by the French Northern Region that has known an important recession because of an industry previously based on coal, textile and steel. This region wishes to foster entrepreneurship in a broad sense, i.e.: an inner innovative spirit in companies, and creations of start-up companies, that is to say all that can produce a durable value in our changing world. Our colleagues are attempting to take a whole educational system in engineering and particularly our "value creation and management" curriculum into account to detect and measure in the short, middle and long term the benefits on the economical context.

\section{References}

ANSI/EIA-632, 1998, Processes for Engineering a System. ANSI Standard.

APTE, 2000, La Méthode APTE (r) d'AV/AF (Paris: Petrelle).

Ben Ahmed, W. And Yannou, B., 2003, Speaking of Interests Rather Than Values Would be Less Confusing: the Example of Product Design. International Journal of Value-Based Management, 16(2).

BERnARD-Bouissieres, J., 2000, Aide à l'élaboration du cahier des charges fonctionnel - Pour une meilleure expression du besoin (Paris : AFNOR).

BigAnd, M., CRAYE, E. AND Deshayes, P., 2000, Project monitoring in a graduate engineering school. IEEE/SMC Transactions, Part C: Applications and reviews, 30(2), pp. 183-188.

Bloch, A. And Manceau, D., 2000, De l'idée au marché. Marketing et stratégie de l'innovation. Collection Vital Roux (Paris : Vuibert).

EN-12973, 2000, Value Management. European standard.

Fernandez, M. G., Seepersad, C. C., Rosen, D. W., Allen, J. K. and Mistree, F., 2001, UtilityBased Decision Support for Selection in Engineering Design. ASME Design Engineering Technical Conferences, 9-12 Sept 2001, Pittsburgh, USA/PA, Paper number DETC2001-DAC21106.

GOYHENETCHE, M., 1999, Marketing de la Valeur (Paris: INSEP Editions).

Green, P. E. And SRInivasan, V., 1978, Conjoint Analysis in Consumer Research: Issues and Outlook. Journal of Consumer Research, 5.

HigGins, J. M., 1994, 101 creative problem solving technique: The handbook of new ideas for business (New management publishing company).

KaPlan, R. S. AND Norton, D. P., 1996, Using the balanced scorecard as a strategic management system. Harvard Business Review, January-February, pp. 75-87.

Karlsson, C. And Ahlstrom, P., 1997, Perspective: Changing Product Development Strategy: a Managerial Challenge. Journal of Product Innovation Management, 14, pp. 473-484.

LAmbin, J. J., 1991, Le Marketing Stratégique (New-York: Mc Graw Hill).

LimaYem, F., 2001, Modèles de pondération par les méthodes de tri croisé pour l'aide à la décision collaborative en projet. PhD thesis, 23 Nov 2001, Ecole Centrale Paris.

MiLES, L. D., 1961, Techniques of Value Analysis and Engineering (New-York: Mc Graw Hill).

MintzBeRG, H., 1973, The Nature of Managerial Work (New-York: Harper \& Row).

NGassa, A., Bigand, M. AND Yim, P., 2003, A new approach for the generation of innovative concept for product design. International Conference on Engineering Design: ICED'03, Stockholm, Sweden.

Perrin, J., 2001, Analyse de la valeur et valeur économique des biens et services. RFGI: Revue Française de Gestion Industrielle, Special issue on Value Management, 20(2).

PORTER, M., 1986, L'avantage concurrentiel: comment devancer ses concurrents et maintenir son avance. (Paris: Interéditions).

RoY, B., ed., 1985, Méthodologie multicritère d'aide à la décision. SERIE: Production et techniques quantitatives appliquées à la gestion (Paris: Economica).

SAATY, T. L., 1980, The Analytic Hierarchy Process (New-York: McGraw-Hill). 
Yannou B., Bigand M., (2004), A curriculum of value creation and management in engineering. European Journal of Engineering Education, vol. 29(3, DOl: 10.1080/03043790310001658550): p. 355-366

SAVRANSKY, S. D., 2000, Engineering of creativity - Introduction to TRIZ Methodology of Inventive Problem Solving (Boca Raton, Fla: CRC Press).

SENI, D., 2001, Desiderata for an idealized scenario: towards an international masters program in value management. Workshop on towards A VM and VE Educational Framework at Masters Level, The Miles Value Foundation (MVF) and VEAMAC, Fort Lauderdale, Florida, USA.

SteVEnS, S. S., 1951, Mathematics, Measurement and Psychophysics. In Handbook of Experimental Psychology, edited by Luce, Bush and Galanter (New-York: John Wiley \& Sons).

Umeda, Y., Ishit, M., Yoshioka, M., Shimomura, Y. and TomiYama, T., 1996, Supporting Conceptual Design Based on the Function-Behaviour-State Modeler. Artificial Intelligence for Engineering Design, Analysis and Manufacturing, 10, pp. 275-288.

Verzat, C., Quenehen, S., Bachelet, R., Frugier, D. And Giry, Y., 2002, Developing entrepreneurship among students in colleges of engineering. ESISAR 2002: Summer university entrepreneurship in europe: specificities and perspectives, Valence, France.

Wallas, G., 1926, The Art of Thought. (New York: Harcourt Brace).

WoODHEAD, R., 2002, The development of a Value Engineering discipline in universities: A collection of discussion papers. Workshop on Towards A VM and VE Educational Framework at Masters Level, The Miles Value Foundation (MVF) and VEAMAC, Denver, USA.

YANNOU, B., 1999, Proposition de deux nouveaux outils d'aide à la décision en analyse de la valeur, basés sur une définition opérationnelle de la valeur. La Valeur, 81, pp. 7-14.

\begin{abstract}
About the authors
Dr Bernard Yannou is an associate Professor of Industrial and Mechanical Engineering in the Laboratoire Génie Industriel of Ecole Centrale of Paris, France. He received a M. Sc. (1988) in Mechanical Engineering and a Ph. D. (1994) in Industrial Engineering from Ecole Normale Supérieure of Cachan. His research interests are centred on the preliminary design of products: functional modeling and reasoning, conceptual design, uncertainty in design, decision-based design and value indicators for driving a design process. He is also an administrator of the French association of Value Analysis and Management, AFAV. He founded in 2000 the VAFORE mailing list for exchanging views on VAlues and Functional modeling on a REsearch viewpoint.

Dr. Michel Bigand is an Associate Professor of Computer Science and Project Management in Ecole Centrale of Lille (France). He received a M. Sc. (1980) from Ecole Normale Supérieure de Cachan in Mechanical Engineering, and a Ph. D. (1988) from Paris 6 University (Laboratoire de Mécanique et Technologie). His research activities concern the design systems engineering, the product lifecycle management, and their associated information systems. He is the headmaster of the European Technological Institute of Entrepreneurship and Management (ITEEM) of Lille that trains in five years entrepreneurial engineers. This institute is supervised by an engineering college (Ecole Centrale Lille) and a business school (Ecole Supérieure de Commerce de Lille) so as to train future company heads.
\end{abstract}

